BMJ Open

Diabetes

Research

\& Care

\title{
Mentored implementation to initiate a diabetes program in an underserved community: a pilot study
}

\author{
Elizabeth M Vaughan (D) ,' Aanand D Naik, ${ }^{1,2,3}$ Amber B Amspoker, ${ }^{2,3}$ \\ Craig A Johnston, ${ }^{4}$ Joshua D Landrum, ${ }^{5}$ Ashok Balasubramanyam, ${ }^{1}$ \\ Salim S Virani, ${ }^{1,2,3}$ Christie M Ballantyne, ${ }^{1}$ John P Foreyt ${ }^{1}$
}

\begin{abstract}
To cite: Vaughan EM, Naik AD, Amspoker AB, et al. Mentored implementation to initiate a diabetes program in an underserved community: a pilot study. BMJ Open Diab Res Care 2021;9:e002320. doi:10.1136/ bmjdrc-2021-002320
\end{abstract}

\begin{abstract}
- Additional supplemental material is published online only. To view, please visit the journal online (http://dx.doi. org/10.1136/bmjdrc-2021002320).
\end{abstract}

Received 8 April 2021 Accepted 18 July 2021

Check for updates

\section{(c) Author(s) (or their} employer(s)) 2021. Re-use permitted under CC BY-NC. No commercial re-use. See rights and permissions. Published by BMJ.

${ }^{1}$ Department of Medicine, Baylor College of Medicine, Houston, Texas, USA

${ }^{2}$ Health Policy, Quality \& Informatics Program, Michael E. DeBakey VA Medical Center, Houston, Texas, USA

${ }^{3}$ Houston Center for Innovations in Quality, Effectiveness, and Safety (IQuESt), Houston, Texas, USA

${ }^{4}$ Department of Health and Human Performance, University of Houston, Houston, Texas, USA

${ }^{5}$ School of Health Professions, Baylor College of Medicine, Houston, Texas, USA

Correspondence to Dr Elizabeth M Vaughan; elizabeth.vaughan@bcm.edu

\section{ABSTRACT}

Introduction Community clinics often face pragmatic barriers, hindering program initiation and replication of controlled research trial results. Mentoring is a potential strategy to overcome these barriers. We piloted an inperson and telehealth mentoring strategy to implement the Telehealth-supported, Integrated Community Health Workers (CHWs), Medication-access, group visit Education (TIME) program in a community clinic.

Research design and methods Participants $(n=55)$ were low-income Latino(a)s with type 2 diabetes. The study occurred in two, 6-month phases. Phase I provided proof-ofconcept and an observational experience for the clinic team; participants $(\mathrm{n}=37)$ were randomized to the intervention (TIME) or control (usual care), and the research team conducted TIME while the clinic team observed. Phase II provided mentorship to implement TIME, and the research team mentored the clinic team as they conducted TIME for a new single-arm cohort of participants $(n=18)$ with no previous exposure to the program. Analyses included baseline to 6-month comparisons of diabetes outcomes (primary outcome: hemoglobin A1c (HbA1C)): phase I intervention versus control, phase II (within group), and research-run (phase I intervention) versus clinicrun (phase II) arms. We also evaluated baseline to 6-month CHW knowledge changes.

Results Phase I: compared with the control, intervention participants had superior baseline to 6-month improvements for $\mathrm{HbA} 1 \mathrm{C}$ (mean change: intervention: $-0.73 \%$ vs control: $0.08 \%, p=0.016)$, weight $(p=0.044)$, target HbA1c $(p=0.035)$, hypoglycemia $(p=0.021)$, medication non-adherence $(p=0.0003)$, and five of six American Diabetes Association (ADA) measures $(\mathrm{p}<0.001-$ 0.002). Phase II: participants had significant reductions in HbA1c (mean change: $-0.78 \%, p=0.006$ ), diastolic blood pressure $(p=0.004)$, body mass index $(0.012)$, weight $(p=0.010)$, medication non-adherence $(p<0.001)$, and six ADA measures $(p=0.007-0.005)$. Phase I intervention versus phase II outcomes were comparable. CHWs improved knowledge from pre-test to post-tests $(p<0.001)$. Conclusions A novel, mentored approach to implement TIME into a community clinic resulted in improved diabetes outcomes. Larger studies of longer duration are needed to fully evaluate the potential of mentoring community clinics.

\section{INTRODUCTION}

Diabetes initiatives are greatly needed in resource-limited settings. The majority $(80 \%)$

\section{Significance of this study}

What is already known about this subject?

- Diabetes initiatives are greatly needed in underserved settings, but community clinics have significant barriers that hinder program initiation.

- Our research team previously targeted diabetes disparities by pioneering a multidemensional diabetes program that includes community health workers (CHWs) into community clinics and found that participants significantly improved outcomes.

- It was unclear if pragmatic barriers faced by community clinics would hinder the ability to reproduce the results of the clinical trial.

What are the new findings?

- An in-person and telehealth mentoring strategy with the research team to the clinic team is a promising strategy to implement diabetes programs into community clinics.

- The intervention resulted in significant improvements in hemoglobin A1c, blood pressure, weight, medication adherence, hypoglycemic events, and preventive care for both the research and clinic team cohorts.

- Clinic team outcomes were comparable to those of the research team.

How might these results change the focus of research or clinical practice?

- This study demonstrated that a novel mentoring approach to implement a multidimensional diabetes program into a community clinic resulted in significantly improved clinical outcomes, which were comparable to those of the research team.

- The CHW peer mentoring aspect of the program is particularly promising to improve outcomes and sustainable healthcare for underserved populations.

of individuals with diabetes are from lowincome and middle-income countries. ${ }^{1-3}$ Diabetes-related disparities are rooted in poverty, diminished access to care, and limited literacy. ${ }^{3}$ The prevalence of diabetes among minorities is increasing exponentially, costing >US\$400 billion in annual 
expenditures. ${ }^{4}{ }^{5}$ Community clinics face significant barriers to provide sustainable programs due to limited infrastructure for training and supervision, logistical burdens, and time constraints, often resulting in illtrained, unsupported staff. ${ }^{6}$

In prior work, we pioneered combining four individually validated strategies at a community clinic serving low-income minorities to target diabetes disparities in the Telehealth-supported, Integrated Community Health Workers (CHWs), Medication-access, group visit Education (TIME) trial. ${ }^{7}$ TIME participants resulted in significantly improved hemoglobin A1c (HbA1c) levels, systolic and diastolic blood pressure, and adherence to American Diabetes Association (ADA) guidelines compared with a control group receiving usual care. ${ }^{7}$ The next step is to translate TIME to clinic settings outside of a structured research environment.

TIME uses group visits, a well-established model to improve outcomes and access to care.$^{8-11}$ Group visits differ from regular care in that they are integrated, shared appointments that include a 1:1 provider medical appointment and education. ${ }^{8}$ The provider encounter separates them from diabetes self-management education, which does not have this component. ${ }^{12}$ Group visits have demonstrated a high degree of patient satisfaction; ${ }^{13}$ a 30 -year review of published group visits found that they were effective in improving both patient and physician satisfaction, increasing quality of life and care, and decreasing system burden, for example, emergency department visits. ${ }^{14}$ The patient groups often include low-income minority participants, so the program would benefit from addressing cultural barriers. ${ }^{11}$ Therefore, as part of the group visit team, we incorporated CHWs, non-medical, trusted members of communities sharing similar language, culture, ethnicity, and educational backgrounds who work with healthcare teams to bridge patients to health systems. ${ }^{15-18}$ Consistent with other studies, ${ }^{1619}$ we have found that patients are highly satisified with CHWs. ${ }^{720}$ We also found that telehealth was instrumental in providing CHW support as well as improving CHW-patient communication. Beyond their usual role as educators, CHWs provided important insights into improving medication adherence and access. ${ }^{720}$

Although our research team successfully implemented TIME, it was unclear if pragmatic barriers faced by community clinics would hinder program initiation and their ability to reproduce the results of the clinical trial. Peer mentoring, communication from a trained person to an individual at a similar career stage who is naive or new to a concept, is a potential strategy to overcome these implementation barriers. ${ }^{21}$ Specifically, mentoring addresses logistical and personnel impediments by providing cost-effective, time-efficient, and accessible supervision. ${ }^{6}$ High-impact investigations have demonstrated that mentors are effective in overcoming barriers to program initiation and treatment in low-income settings. ${ }^{622}$ However, this strategy has not been explored in the context of CHWs. The goal of this study was to pilot an in-person and telehealth mentoring strategy for community clinics to implement the TIME program into a community clinic serving low-income Latino(a)s with type 2 diabetes. To evaluate efficacy, we assessed baseline to 6-month diabetes markers including $\mathrm{HbAlc}$ changes (primary outcome). We hypothesized that TIME participants would have significant improvements in diabetes markers, and the outcomes would be similar for research and clinic teams.

\section{METHODS}

The study occurred at a non-profit community clinic in Houston, Texas, serving uninsured minorities who earned $\leq 150 \%$ of the federal poverty level. There were two, 6-month phases; phase I served a dual purpose: (1) establish proof of concept for TIME at a study site naïve to the program. This was achieved by a randomized clinical trial comparing outcomes of intervention (TIME) participants versus control (usual care) individuals, and (2) provide an observational experience for the clinic team. Specifically, during phase I, the research team conducted TIME while the clinic team observed the intervention. The purpose of phase II was to provide mentorship to implement TIME, which was achieved by the clinic team conducting TIME for a new single-arm cohort of participants not previously exposed to the intervention with concurrent research team support.

\section{TIME program}

TIME has been detailed previously. ${ }^{7}{ }^{20}$ It includes six, monthly group visits and weekly CHW-participant mobile health (mHealth) ${ }^{23}$ contact followed by an additional bimonthly CHW-participant bimonthly contact for 6 months. CHW-participant contact includes coaching (eg, adherence, glucose levels, reminders), and the encounters are reported weekly to the study principal investigator (PI) (physician). Group visits are conducted in Spanish and include a $30 \mathrm{~min}$ large group diabetes education class, three $30 \mathrm{~min}$ breakout sessions, and a healthy meal. CHWs lead two of the breakout sessions (behavioral and social), focusing on barriers to care. In the third breakout session (medical), participants undergo vital sign monitoring, laboratory testing, and a 1:1 provider visit for medication management. The study PI and CHWs meet weekly via telehealth (video conferencing $)^{24}$ for training and support.

Patient safety is a major emphasis. CHWs receive detailed, ongoing education on diabetes medications, adverse reactions, urgent versus non-urgent concerns, standard of care guidelines, and Health Insurance Portability and Accountability Act (HIPAA). ${ }^{725-28}$ CHWs and providers communicate via mHealth for issues that need attention prior to team meetings. Only providers give medical advice. We distribute glucometers with monthly test strips to participants and provide in-person demonstrations and written safety parameters. Retention is a known problem in low-income settings. Therefore, CHW 
training includes identifying participant-system barriers, intentional participant socialization, and room set-up for a welcoming environment. We provide an on-site laboratory, expanded pharmacy hours, and an opportunity to win a US\$20 grocery store gift card/group visit for attendance. ${ }^{29}$ Clinic sites are equipped with psychiatry and spiritual care referral systems if indicated.

\section{Intervention}

The theoretical framework for the CHW mentor model included five key implementation components based on prior implementation work: (1) training (face-to-face interactions), (2) assessment (pre-test/post-test), (3) individualized support, (4) quality improvement (direct observation), and (5) support (team meetings). ${ }^{30}$

Eligible participants were adults ( $\geq 18$ years) with type 2 diabetes (HbAlc $\geq 6.5 \%)$, self-identified as Latino(a), and Spanish-speaking. Individuals were excluded if they had a condition that could lead to unreliable HbA1c levels ${ }^{31}$ or were not appropriate to treat in a group setting, for example, pregnancy, significantly impaired cognition. Phase I participants were identified primarily by the clinic database that filtered for Latino(a)/Hispanic with diabetes (International Classification of Diseases, 10th Edition E11:9, E11:X) and phase II by clinic referrals. Study staff called eligible individuals to explain the study. Interested individuals were invited to the clinic to obtain written consent and baseline HbA1c, blood pressure, height, and weight. A study physician confirmed eligibility with a secondary chart review. To achieve randomization in phase I, we used an automatic number generator to achieve block randomization in groups of four for each study arm. ${ }^{32}$ Individuals living in the same household were randomized to the same arm.

Phase I control participants received usual care in the clinic, which averages quarterly provider appointments in addition to opportunities for group nutrition education, food bank programs, on-site pharmacy, and specialty referral including ophthalmology. They did not have contact with CHWs.

Reflecting the study population, eligible CHWs were self-identified Latino(a) who were Spanish-speaking and lived in similar areas as identified by zip code. Texas is one of the most stringent states for CHW certifications; CHW and CHW-Instructor (CHW-I) certifications each require 160 hours of classwork or 1000 hours of community service and 20 hours of continuing education biennially to re-certify. ${ }^{15} \mathrm{CHWs}$ were not required to have diabetes. Research team CHWs also obtained their CHW-I certification and maintained an active Texas CHW certification. The research CHW-Is served as CHWs in our group from prior studies. ${ }^{720}$ We recruited clinic CHWs from a church near the clinic site and assisted in obtaining their Texas CHW certifications prior to study initiation. The PI provided a 3-hour, telehealth training on research procedures, confidentiality, and the TIME program overview for CHWs. In addition, the PI met with clinic providers monthly for a 30 min telehealth training throughout both phases and conducted a 1 hour educational session with topics similar to the CHW training and low-cost medication education. We defined the research team as the study PI, co-investigators, and six CHW-Is and the clinic team as the two providers and six CHWs; they met weekly via telehealth throughout phase II and in-person at each group visit.

The COVID-19 pandemic started at the end of phase I (September 2019-March 2020) and lasted throughout phase II (June-November 2020). During the pandemic, we stratified group visits into three instead of one cohort to adhere to social distancing protocols, provided COVID-19 screening 24 hours before and the day of clinic, and followed current Centers for Disease Control and Prevention guidelines masks and face shields.

\section{Measures}

The study aimed to evaluate the efficacy of the clinic team leading TIME and, therefore, the primary study outcome was baseline to 6-month HbAlc change for phase II participants. Secondary outcomes included viewing potential differences between the research versus clinic team by comparing the research team-led arm (phase I intervention) to the clinic team-lead arm (phase II). Other outcomes included baseline to 6-month changes of HbAlc for other study arms, blood pressure, body mass index (BMI), weight, hypoglycemia, achieving target HbAlc $(<7.0 \%),{ }^{25}$ medication adherence, six ADA preventive measures (retinal, comprehensive foot exam, microalbuminuria, and $\mathrm{B}_{12}$ screenings; influenza vaccination; appropriately dosed statin), and CHW pre-test/ post-test. ${ }^{25}$

\section{Measurement techniques}

Clinical measures reflected standards of care practices, for example, recheck blood pressure if $\geq 140 / 90$ after 15 min. ${ }^{25}$ Study staff obtained participant baseline and month-6 HbA1c, blood pressure, height, and weight levels in-person. Due to COVID-19 restrictions, research staff could not obtain in-person 6-month measurements for all participants and, therefore gathered information via the electronic medical record (EMR). We defined baseline and 6 months as months 0 and $6 \pm 4$ weeks, respectively.

We obtained hypoglycemic events (defined as $\geq 3$ episodes of glucose $<80 \mathrm{mg} / \mathrm{dL}$ ), diabetes medication adherence, and ADA measures via EMRs. Measuring medication adherence is challenging in low-income settings due to eligibility variations and use of multiple pharmacies, resulting in unreliable objective measurements, for example, several bottles of the same medication. ${ }^{33}$ Therefore, we chose not to conduct pill counts or obtain pharmacy records. Participants in all arms were instructed to bring their medications to provider encounters. Since providers routinely mentioned medication adherence in the EMR, we used these notes for adherence information. To be considered adherent participants took all diabetes medications as prescribed. 
ADA measures were recorded as adherent if achieved by the desired time point, that is, baseline microalbuminuria was marked adherent if it occurred from baseline to 1 year prior. $^{25}$

\section{Surveys and pre-test/post-test}

We gathered baseline and 6-month qualitative and quantitative survey data to assess changes in relaxation, spirituality, social support, feelings of health, and program satisfaction. At 6 months, we also inquired about the burden of home glucose monitoring for TIME participants. This 21-question survey combined prior validated surveys on these topics as well as our TIME program satisfaction questionnaire. ${ }^{735}$ To assess change of knowledge clinic, CHWs took a pre-test and post-test, separated by 6 months. This 49-question test included our 25-question diabetes medication test published previously and the 24-question Starr County Education Study Diabetes Knowledge Test that has demonstrated validity and reliability in English and Spanish. ${ }^{36} 37$

\section{Statistical analyses}

Analyses were intention-to-treat and involved betweengroup comparisons (phase I intervention vs control; phase I intervention vs phase II) as well as within-group comparisons (phase I). For between-group analyses, we used independent samples t-tests to examine group differences for change from baseline to 6 months for continuous outcomes (ie, HbAlc, systolic and diastolic blood pressure, BMI, weight). The $\chi^{2}$ tests were used to examine between-group differences in dichotomous outcomes (ie, weight loss, HbAlc target, change in hypoglycemia, each of the six ADA markers, medication non-adherence). When outcomes were not normally distributed or cell sizes were small, we used the non-parametric Wilcoxon Mann-Whitney U test for continuous outcomes or Fisher's exact test for dichotomous outcomes. For withingroup comparisons, we used dependent samples t-tests and the McNemar test for continuous and dichotomous outcomes, respectively. Due to COVID-19 restrictions noted in Measurement Techniques, we were not able to obtain 6-month data for 10 participants and, therefore, averaged their 3-month HbAlc, blood pressure, and weight values with 9-month levels. Month-3 levels were not available for four participants and, therefore, baseline values were used. For survey data and CHW pre-test/ post-test, we obtained an item mean score. If an answer was omitted, it was excluded from the analyses. To address missing data, we repeated all between-group and withingroup comparisons of primary outcomes using multiple imputation procedures PROC MI and MI ANALYZE in SAS. Analyses were conducted using SAS V.9.4 (SAS Institute, Cary, North Carolina, USA).

We used a sample size of 15-22 participants/arm $(\mathrm{n}=55)$, which was appropriate for several reasons. A group visit cohort typically is limited to $12-25$ individuals, resulting in a range of 36-75 total potential participants for the three arms. ${ }^{98}$ The nature of the study was a pilot investigation, not warranting a formal power calculation. ${ }^{39}$ However, post hoc power calculations ( $G^{*}$ Power $3.129)^{40}$ revealed that with an alpha (two-tailed) $\leq 0.05$, our sample sizes resulted in $80 \%$ power to detect effects (Cohen's d) of HbAlc from baseline to 6 months as small as 0.96 (phase I intervention vs control), 0.70 (phase II), and 0.91 (phase I intervention vs phase II).

\section{RESULTS}

The Consolidated Standards of Reporting Trials diagram (figure 1) illustrates the flow of phases I and II from database extraction to study entry. For phase I, study staff called 238 individuals, of which 140 individuals were inititally excluded primarily due to inability to contact $(\mathrm{n}=96)$. Of the 98 eligible and interested individuals, $59 \%$ did not show and $3 \%$ were excluded during secondary physician review, resulting in 37 individuals randomized into study arms. Two block randomizations in groups of four for individuals and pairs in same household resulted in an uneven distribution of intervention $(n=22)$ and control $(n=15)$ individuals. ${ }^{32}$ For phase II, we attempted to contact 35 individuals of which 14 individuals were excluded mostly due to inability to contact $(n=5)$. Of the 21 eligible and interested individuals, three were excluded during secondary physician review, resulting in 18 consented participants. Attrition was low in both phases $(0 \%-13.6 \%)$.

Group visit attendance was high for both phases. For phase I (intervention), the mean attendance was five of six sessions, with $91 \%$ present for $\geq 50 \%$ and $46 \%$ for all six classes. For phase II, the mean attendance was five of six sessions, with all $(100 \%)$ present for $\geq 50 \%$ and $50 \%$ for all six classes. Additionally, CHWs successfully contacted individuals between group visits $89 \%$ of attempts (mean 21.3/24) during phase I (intervention) and $87 \%$ (mean 20.8/24) during phase II.

Table 1 illustrates the baseline demographics for participants by study phase. There were no significant differences between phase I arms in terms of sex, employment, documentation status, medication treatment or adherence, hypoglycemia, preventive care, diabetes duration, age, HbAlc, blood pressure, BMI, weight, and cholesterol. Analyses comparing the demographics of phase I (intervention) to phase II revealed that there were more receiving oral hypoglycemics only $(\mathrm{p}=0.033)$ and with urine microalbumin screening $(\mathrm{p}<0.001)$ in phase I and with medication non-adherence $(\mathrm{p}=0.001)$ and hypoglycemia events $(\mathrm{p}=0.042)$ in phase II.

Table 2 shows the baseline to 6-month changes for phase I arm comparisons, phase II, and phase I (intervention) versus phase II. Phase I between-group comparisons revealed superior outcomes for the intervention compared with the control arm for: HbAlc (all) (intervention: $7.61 \%-6.99 \%$, mean change $-0.73 \%, 95 \% \mathrm{CI}$ ( -1.1 to 0.3 ), control: $7.66 \%-7.74 \%$, mean change 0.08 , $95 \%$ CI $(-0.4$ to 0.5$) ; \mathrm{p}=0.016)$, HbA1c (uncontrolled) (intervention: $8.33 \%-7.30 \%$, mean change $-1.03,95 \% \mathrm{CI}$ 


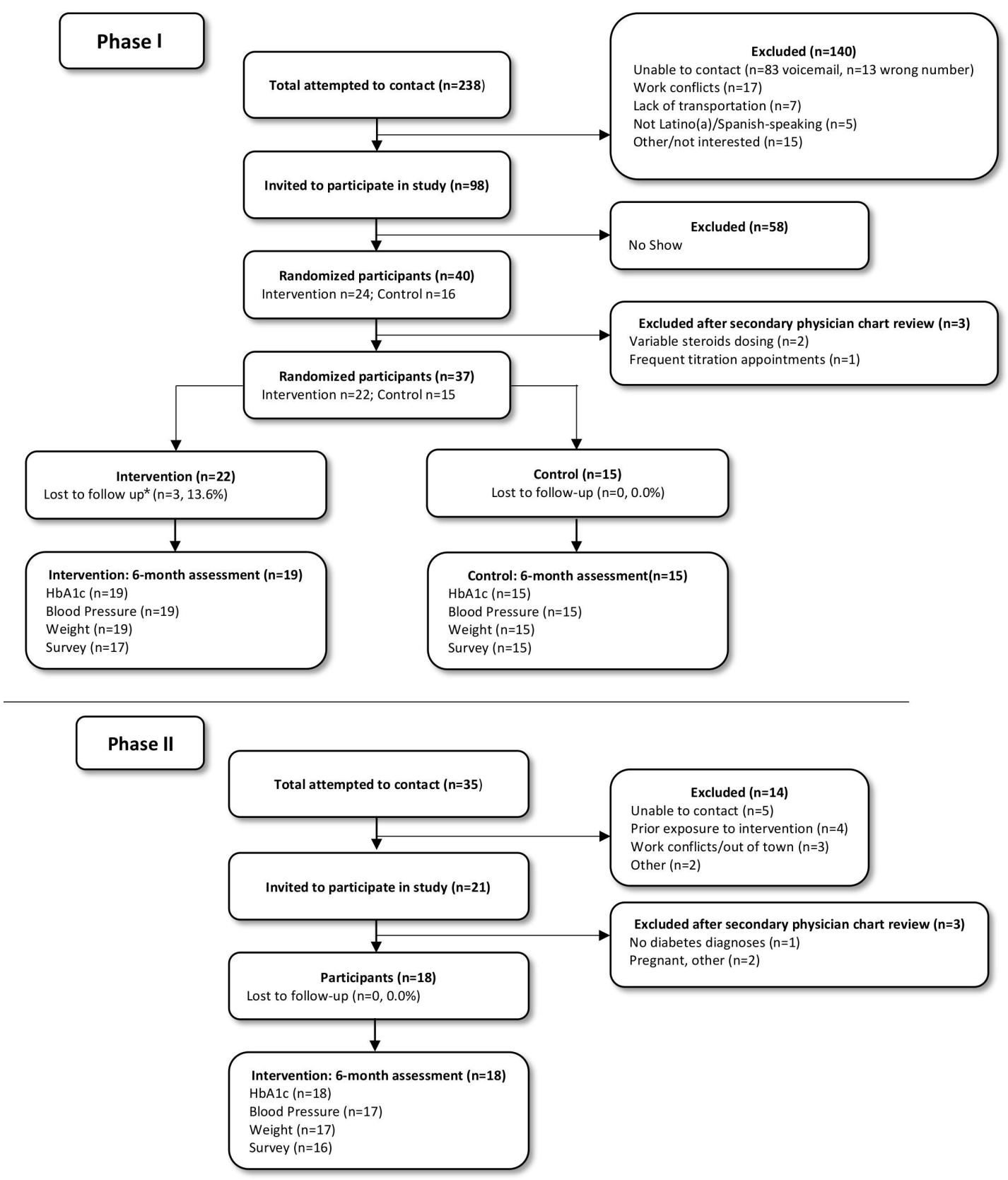

Figure 1 Consolidated Standards of Reporting Trials diagram of phase I and phase II. *Lost to follow-up defined as the inability to contact the participant at month 6. HbA1c, hemoglobin A1c.

$(-1.5$ to -0.5$)$, control: $8.39 \%-8.20 \%$, mean change $0.04,95 \%$ CI $(-0.7$ to 0.8$) ; \mathrm{p}=0.011)$, weight $(\mathrm{p}=0.044)$, HbAlc target $(\mathrm{p}=0.035)$, hypoglycemia $(\mathrm{p}=0.021)$, and all preventive care measures $(\mathrm{p}<0.001-0.002)$ except urinary albumin $(\mathrm{p}=0.31)$. A greater percentage of individuals in the intervention lost weight than in the control $(68.2 \%$ vs $40.0 \%$, respectively) but this was not significant $(\mathrm{p}=0.094)$. There were no significant differences between arms for blood pressure or BMI.

Phase II within-group comparisons resulted in several areas of significance: HbA1c (all) $(7.55 \%-6.77 \%$, mean change $-0.78,95 \%$ CI $(-1.3$ to -0.3$) ; \mathrm{p}=0.006)$, HbA1c (uncontrolled) $(8.30 \%-6.96 \%$, mean change -1.34 , $95 \%$ CI ( -2.0 to -0.7$) ; \mathrm{p}=0.001)$, diastolic blood pressure
( $\mathrm{p}=0.004)$, BMI (0.012), weight $(\mathrm{p}=0.01)$, and preventive care measurements $(\mathrm{p}=0.005-0.0005)$ (table 2). There were no significant changes for systolic blood pressure or proportion achieving target HbAlc levels.

Baseline to 6-month analyses of the research-team run group (phase I, intervention) versus the clinic-team run group (phase II) revealed no significant differences between groups from baseline to 6 months for HbAlc, systolic blood pressure, BMI, weight, target HbAlc, and preventive care measures except urinary albumin screening $(p=0.0001) \quad$ (table 2). Baseline to 6-month changes in diastolic blood pressure $(\mathrm{p}=0.04)$, hypoglycemia $(p=0.04)$, urinary albumin $(p=0.0001)$, and medication non-adherence $(\mathrm{p}=0.002)$ were significantly 
Table 1 Baseline demographics and clinical information by study phase and arm

\begin{tabular}{|c|c|c|c|c|c|}
\hline \multirow[b]{2}{*}{ Variable } & \multicolumn{3}{|c|}{ Phase I $(n=37$, intervention=22) } & \multirow{2}{*}{$\begin{array}{l}\text { Phase II }(n=18) \\
\text { Intervention }\end{array}$} & \multirow{2}{*}{$\begin{array}{l}\text { Phase I intervention } \\
\text { versus phase II } p \text { value }\end{array}$} \\
\hline & Intervention & Control & $P$ value & & \\
\hline & $n(\%)$ & $n(\%)$ & & $n(\%)$ & \\
\hline Sex (male) & $9(40.9)$ & $8(53.3)$ & 0.470 & $9(50.0)$ & 0.516 \\
\hline \multicolumn{6}{|l|}{ Work } \\
\hline Domestic & $10(45.5)$ & $6(40.0)$ & 0.470 & $7(38.9)$ & 0.656 \\
\hline Maintenance, construction & $3(13.6)$ & $3(20.0)$ & & $5(27.8)$ & \\
\hline Food service, transportation & $5(22.7)$ & $1(6.7)$ & & $1(5.5)$ & \\
\hline Unemployed/Unknown, other & $4(18.2)$ & $5(33.3)$ & & $5(27.8)$ & \\
\hline \multicolumn{6}{|l|}{ Legal status } \\
\hline Documented & $14(63.6)$ & $9(60.0)$ & 0.829 & $11(61.1)$ & 0.398 \\
\hline Undocumented & $8(36.4)$ & $6(40.0)$ & & $7(38.9)$ & \\
\hline \multicolumn{6}{|l|}{ Diabetes therapy } \\
\hline None (lifestyle only) & $2(9.1)$ & $1(6.7)$ & 0.798 & $2(11.2)$ & 0.837 \\
\hline Orals only & $18(81.8)$ & $11(73.3)$ & 0.551 & $9(50.0)$ & 0.033 \\
\hline Insulin only & $0(0.0)$ & $0(0.0)$ & 1.0 & $1(5.5)$ & 0.274 \\
\hline Orals+insulin & $2(9.1)$ & $3(20.0)$ & 0.354 & $6(33.3)$ & 0.059 \\
\hline Hypoglycemia* & $1(4.5)$ & $1(6.7)$ & 0.786 & $5(22.8)$ & 0.042 \\
\hline Medication non-adherence $\dagger$ & $5(25.0)$ & $3(21.5)$ & 0.848 & $11(68.8)$ & 0.001 \\
\hline \multicolumn{6}{|l|}{ Prevention $(n) \ddagger$} \\
\hline $\mathrm{B}_{12}$ screening & $0(0.0)$ & $0(0.0)$ & 1.0 & $0(0.0)$ & 1.0 \\
\hline Statin therapy & $9(40.9)$ & $10(66.7)$ & 0.131 & $12(66.7)$ & 0.369 \\
\hline Foot exam & $4(18.2)$ & $0(0.0)$ & 0.085 & $0(0.0)$ & 0.019 \\
\hline Influenza vaccine & $3(13.6)$ & $4(26.7)$ & 0.334 & $8(44.0)$ & 0.174 \\
\hline Eye exam & $8(36.4)$ & $7(46.7)$ & 0.544 & $7(38.9)$ & 0.425 \\
\hline \multirow[t]{2}{*}{ Urinary albumin } & $20(90.9)$ & $10(66.7)$ & 0.068 & $5(27.8)$ & $<0.001$ \\
\hline & Mean $( \pm S D)$ & Mean $( \pm S D)$ & & Mean ( \pm SD) & \\
\hline Diabetes duration (years) & $8.4 \pm 6.7$ & $11.5 \pm 10.7$ & 0.288 & $12.4 \pm 9.6$ & 0.236 \\
\hline Age (years) & $52.5 \pm 7.8$ & $57.7 \pm 9.2$ & 0.08 & $58.7 \pm 10.7$ & 0.194 \\
\hline \multicolumn{6}{|l|}{ HbA1c (\%) } \\
\hline All & $7.61 \pm 1.2$ & $7.66 \pm 1.3$ & 0.903 & $7.55 \pm 1.3$ & 0.748 \\
\hline Uncontrolled§ & $8.33 \pm 1.0$ & $8.39 \pm 1.2$ & 0.900 & $8.30 \pm 1.0$ & 0.738 \\
\hline \multicolumn{6}{|l|}{ Blood pressure $(\mathrm{mmHg})$} \\
\hline Systolic & $132.6 \pm 14.3$ & $137.9 \pm 21.0$ & 0.369 & $140.1 \pm 29.3$ & 0.517 \\
\hline Diastolic & $75.9 \pm 12.4$ & $74.0 \pm 8.0$ & 0.651 & $81.1 \pm 11.6$ & 0.458 \\
\hline BMI $\left(\mathrm{kg} / \mathrm{m}^{2}\right)$ & $32.3 \pm 5.7$ & $30.2 \pm 4.0$ & 0.216 & $31.4 \pm 3.9$ & 0.947 \\
\hline Weight (lbs) & $182.8 \pm 35.6$ & $170.9 \pm 23.5$ & 0.285 & $179.0 \pm 24.8$ & 0.725 \\
\hline \multicolumn{6}{|l|}{ Cholesterol (mmol/L) } \\
\hline Total & $179.1 \pm 40.5$ & $181.8 \pm 39.3$ & 0.872 & $171.9 \pm 46.6$ & 0.293 \\
\hline Triglycerides & $195.6 \pm 118.0$ & $121.9 \pm 51.8$ & 0.101 & $131.8 \pm 47.6$ & 0.973 \\
\hline $\mathrm{HDL}$ & $46.1 \pm 10.1$ & $52.6 \pm 8.7$ & 0.846 & $51.6 \pm 8.5$ & 0.905 \\
\hline LDL & $96.8 \pm 32.9$ & $105.5 \pm 35.4$ & 0.537 & $94.5 \pm 31.1$ & 0.352 \\
\hline
\end{tabular}

${ }^{*} \geq 3$ episodes $<80 \mathrm{mg} / \mathrm{dL}$ weekly during the last month.

†Excludes individuals not receiving hypoglycemics: phase I intervention and phase II ( $n=2 /$ arm); phase I control $(n=1)$.

$\ddagger$ Guideline adherence as per American Diabetes Association. Data were gathered by chart review at the following time points: baseline (appropriately dosed statin; $B_{12}$ screening), baseline to 1 year prior (annual screenings: retinal, foot, urine, influenza vaccination). ${ }^{25}$ $\S \mathrm{HbA} 1 \mathrm{c} \geq 7 \%$ (or $\geq 7.5 \%$ if 65 years or older).

$\mathrm{BMI}$, body mass index; HbA1c, hemoglobin A1c; HDL, high-density lipoprotein; LDL, low-density lipoprotein. 


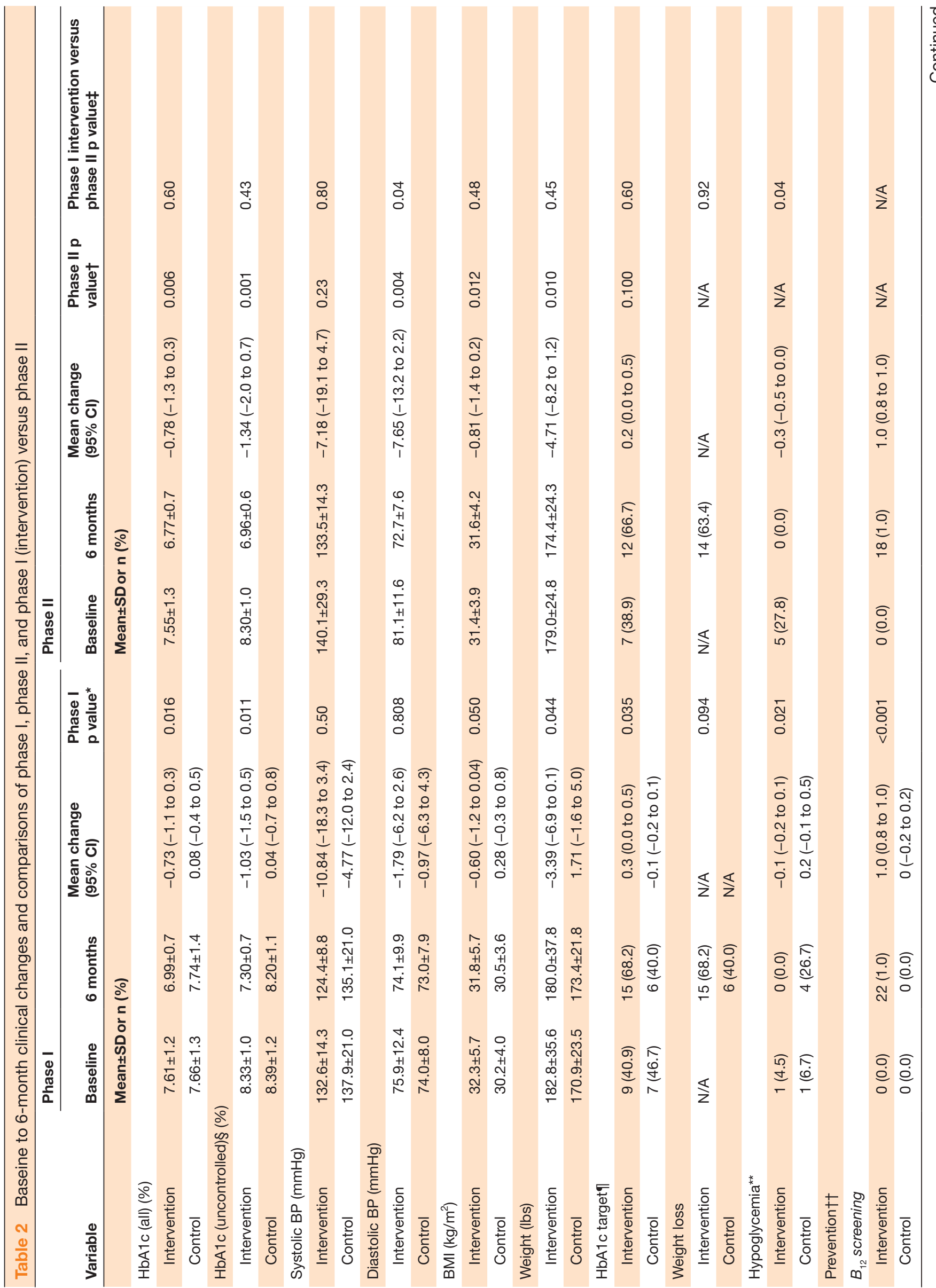




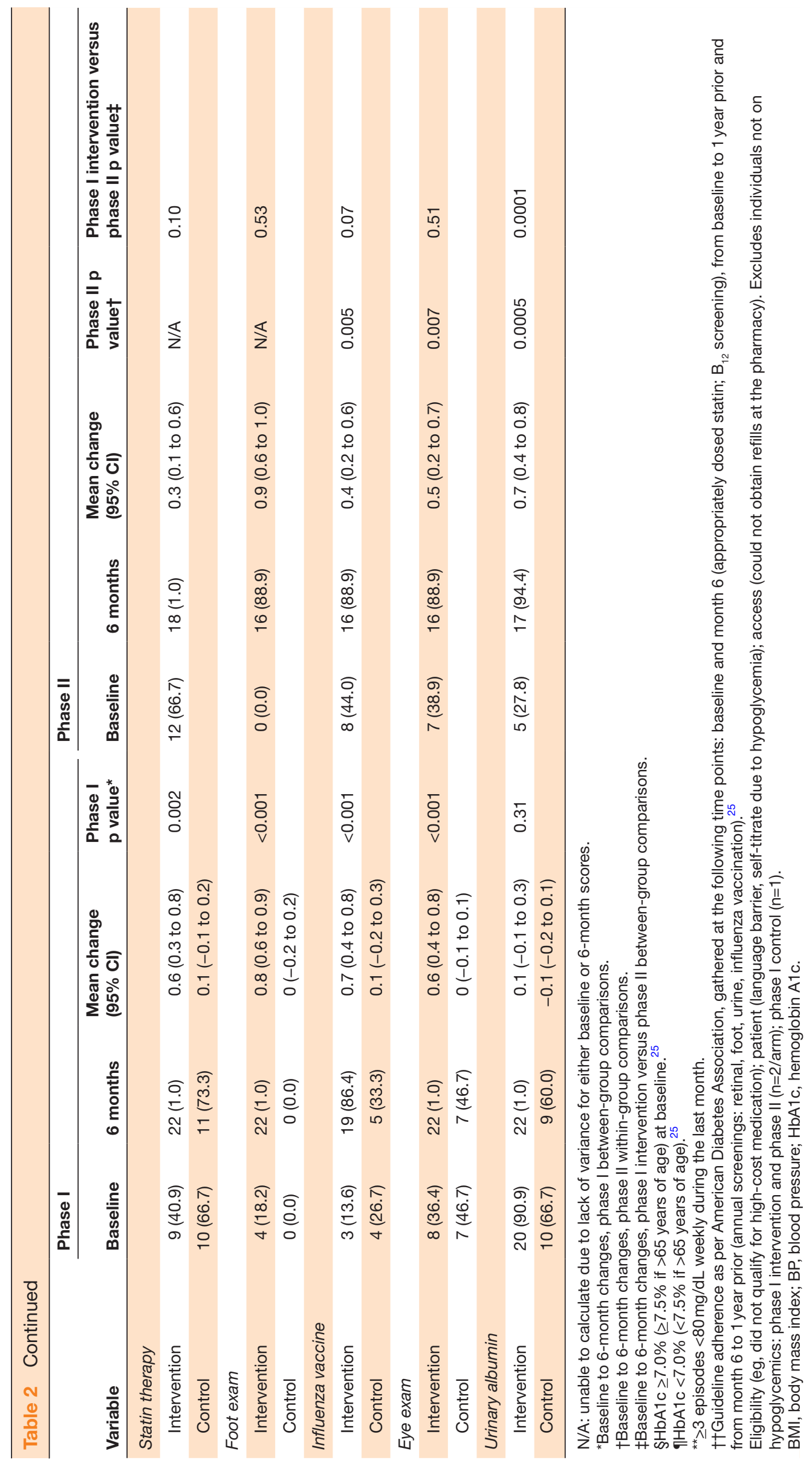




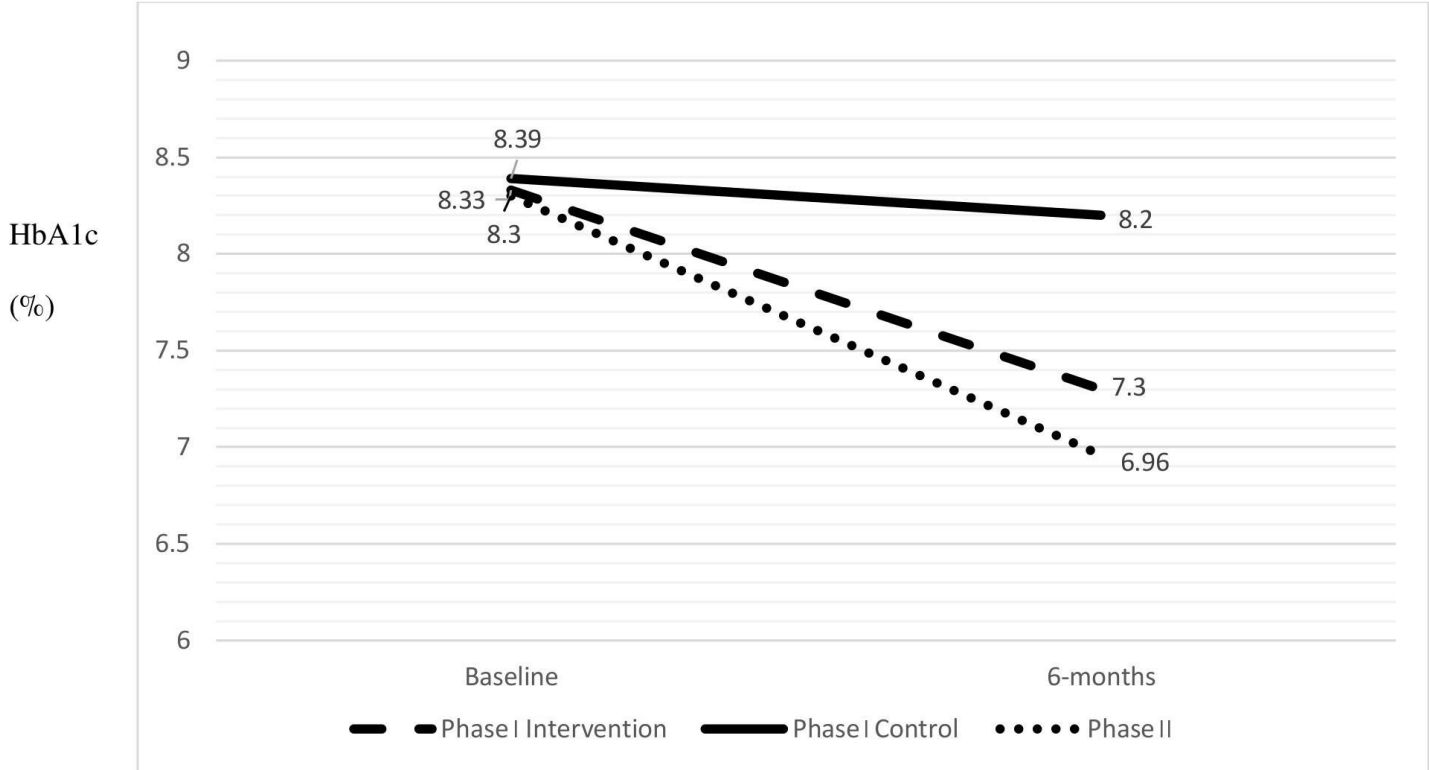

Figure 2 Comparison of hemoglobin A1c (HbA1c) levels by study phase and arm (represents HbA1c levels of individuals who started the study uncontrolled, for example, $\left.\mathrm{HbA} 1 \mathrm{c}>7 \%{ }^{25}\right)$. Phase I intervention (mean change $-1.03 \%, 95 \% \mathrm{Cl}(-1.5$ to -0.5$)$ ) versus control (mean change $0.04 \%, 95 \% \mathrm{Cl}(-0.7$ to 0.8$)$ ), $(\mathrm{p}=0.011)$; Phase II (mean change $-1.34 \%, 95 \% \mathrm{Cl}(-2.0$ to -0.7$)$ ), $(p=0.001))$.

different between arms. Importantly, several areas of significant change from baseline also had significant baseline differences between study arms. Figure 2 depicts HbA1c outcomes between study phases and arms.

There were 34 participants with cases of medication non-adherence at baseline and 6 months for all arms. Intervention individuals had greater improvements in adherence compared with the control arm $(p=0.0003)$, and phase II participants also significantly improved adherence $(p<0.001)$. The most common reasons for medication non-adherence were: patient issues $(50 \%)$ (eg, misunderstanding of insulin dose), eligibility (32\%) (eg, difficulty navigating renewal processes such as in Patient Assistance Programs), and access (18\%) (eg, refill not available in pharmacy). The majority $(67 \%)$ of individuals receiving insulin had medication non-adherence.

The online supplemental appendix illustrates participant survey outcomes. Participants were highly satisfied with the program and CHW involvement. Home glucose monitoring assisted participants in controlling diabetes and did not result in significant adversity. There were no significant differences in relaxation, spirituality, social support, and sense of health for phase I comparisons or phase II. Figure 3 demonstrates that CHWs significantly improved their diabetes knowledge: CHWs averaged 27.3/49.0 (range 17.0-38.0) on the pre-test and 46.0/49.0 (range 43.0-48.0) on the post-test $(\mathrm{p}<0.001)$. All CHWs improved their score. Qualitative data from the clinic

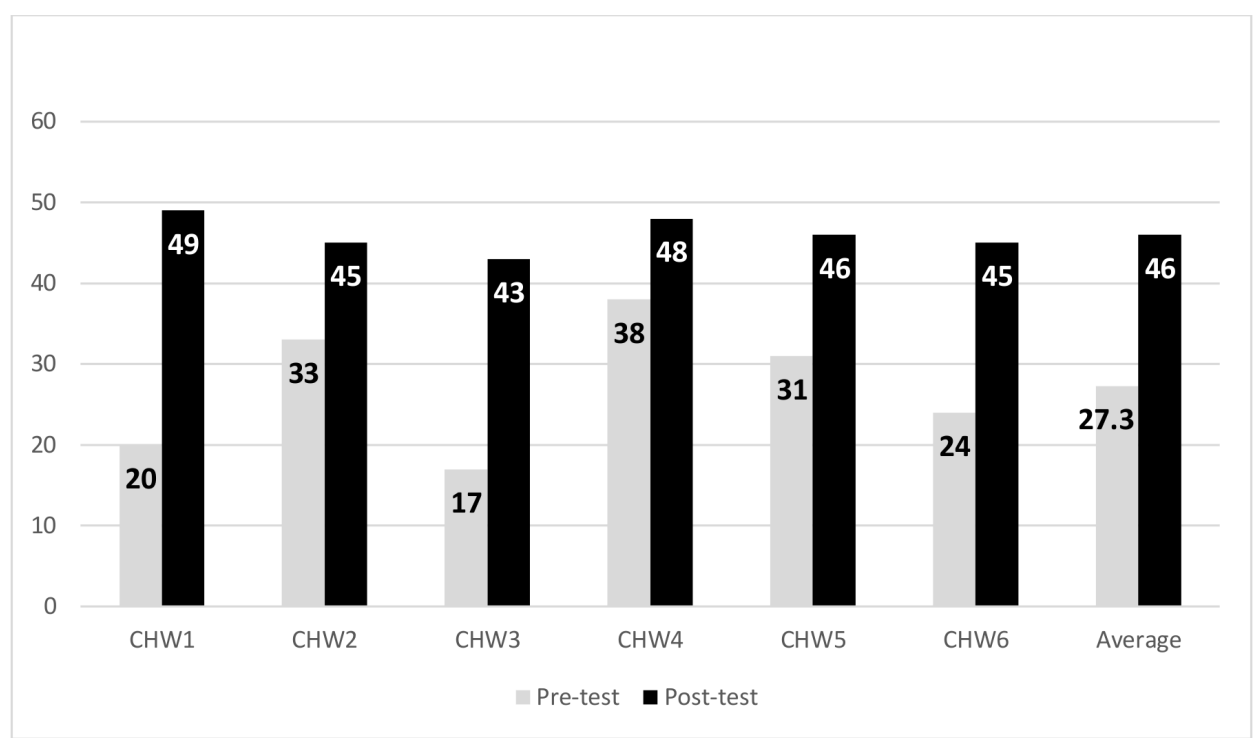

Figure 3 Community health worker $(\mathrm{CHW})$ pre-test and post-test by individual and overall $(\max s c o r e=49)(p<0.001)$. 
team revealed that they greatly enjoyed participation in the program as it allowed active engagement to improve the health of their clinics' patients. In addition, they appreciated the ongoing support and mentorship during their work. Furthermore, conducting weekly meetings after hours and via telehealth enabled $>90 \%$ mean participation for team members.

\section{DISCUSSION}

Diabetes is a morbid chronic disease, and sustainable treatment programs are vital to reduce personal and system burdens. However, community clinics serving resourcelimited individuals often face numerous barriers that hinder program implementation. ${ }^{6}$ This study revealed that a mentoring approach to implement a multidimensional diabetes program into a community clinic resulted in significantly improved clinical outcomes, which were comparable to those of the research team. This is a novel and promising strategy to improve outcomes, particularly in regard to the CHW peer mentoring aspect of the program.

Other forms of mentoring have been widely described in the literature. ${ }^{41}$ A common example of peer mentoring is physician to physician, used by hundreds of hospitals to implement quality initiatives. ${ }^{30}$ CHWs typically do not receive peer mentoring, communication to an individual new to a concept from a trained person at a similar career stage. ${ }^{21}$ An investigation of community-academic research partnerships used physicians to train CHWs to implement a diabetes program for low-income minorities. ${ }^{42}$ Similar to the current study, there was a focus on CHW-led, community-based implementation programs. However, it differed from the current study as there were no significant clinical differences from the intervention and it did not include peer mentoring. ${ }^{42}$

More recent efforts focus on altering mentoring practices for different cultures and regions in low-income/ middle-income settings. ${ }^{6}$ Peer mentoring addresses these issues. For example, we observed that the research team CHW-Is anticipated potential barriers for the clinic team CHWs, for example, transportation, telehealth connectivity, navigating participant concerns. CHW-Is also helped CHWs antiparticipant barriers including understanding medication instructions, navigating eligibility programs, mHealth connectivity, and reminders of upcoming group visits. We credit the low attrition rates of the study $(0 \%-13.6 \%)$ and ability to recruit to the CHW mentoring component. Attrition in other studies involving CHWs averages $16.2 \%$ (range $5 \%-27 \%$ ) ${ }^{43}$ Similarly, we believe that the improvements in medication adherence and hypoglycemic events were a reflection of CHW involvement and their ability to communicate, educate, and direct participants in their care. However, with TIME's multidemensional approach to care, variable analysis are needed to help determine the degree the observed effects are related to the intensity of the medical exposure versus the effect of the intervention.
The study had several strengths. We included a novel CHW mentoring initiative, which used telehealth as its centerpiece. Telehealth enhances participant communication, clinic support, and overcomes logistical barriers. In addition, our methodology was strategically planned to ensure clinic feasibilty, time for observation, and a comparison of research to clinic team outcomes. Importantly, we provided a platform for a sustainable program by training a local clinic to run TIME and maintaining ongoing, monthly communication with key clinic stakeholders, that is, medical director, clinic providers. The study is limited in that there may be lack of access to telemedicine in low-income communities. ${ }^{44}$ In addition, the study occurred at one urban clinic site and piloted an observational cohort. Future randomized controlled trials are needed to evaluate these findings in a larger population. In addition, studies are needed to assess other modalities of training and supervising the clinic, for example, remote supervision during group visits to expand clinic mentoring to rural areas.

\section{Conclusions}

This study demonstrates the value of mentoring clinics to successfully implement a diabetes management program. This is a promising modality for sustainable healthcare in underserved settings. Larger randomized studies are warranted to further evaluate this strategy.

Acknowledgements The authors wish to thank the study participants, Community Health Workers (CHWs), CHW-Instructors, and clinical site for their contributions in the study. The authors are grateful for the overwhelming and endless support of the late Dr David J Hyman (1955-2020).

Contributors EMV, JPF, DJH, CAJ, and the CHW-Instructors conceived the presented idea. EMV, DJH, and JDL carried out the experiment. EMV, JDL, and ABA wrote the manuscript with support from CAJ, ADN, SSV, AB, CMB, and JPF. EMV, AB $\mathrm{CMB}, \mathrm{JPF}, \mathrm{DJH}, \mathrm{CAJ}, \mathrm{ADN}$, and SSV developed the theoretical formalism and ABA performed the analytic calculations.

Funding This work was supported by a grant from the National Institutes of Health, National Institute of Diabetes, and Digestive and Kidney Diseases (DK110341; Vaughan, PI). Additional support is provided by the Center for Innovations in Quality, Effectiveness and Safety at the Michael E. DeBakey VA Medical Center, Houston, Texas (CIN 13-413; Naik), and Department of Veterans Affairs, World Heart Federation, and Tahir and Jooma Family (Virani).

Competing interests None declared.

Patient consent for publication Not required.

Ethics approval The study obtained ethics approval by Baylor College of Medicine Institutional Review Board (H40322). All participants gave informed written consent before taking part in the study.

Provenance and peer review Not commissioned; externally peer reviewed.

Data availability statement Data are available upon reasonable request.

Supplemental material This content has been supplied by the author(s). It has not been vetted by BMJ Publishing Group Limited (BMJ) and may not have been peer-reviewed. Any opinions or recommendations discussed are solely those of the author(s) and are not endorsed by BMJ. BMJ disclaims all liability and responsibility arising from any reliance placed on the content. Where the content includes any translated material, BMJ does not warrant the accuracy and reliability of the translations (including but not limited to local regulations, clinical guidelines, terminology, drug names and drug dosages), and is not responsible for any error and/or omissions arising from translation and adaptation or otherwise.

Open access This is an open access article distributed in accordance with the Creative Commons Attribution Non Commercial (CC BY-NC 4.0) license, which permits others to distribute, remix, adapt, build upon this work non-commercially, 
and license their derivative works on different terms, provided the original work is properly cited, appropriate credit is given, any changes made indicated, and the use is non-commercial. See: http://creativecommons.org/licenses/by-nc/4.0/.

ORCID iD

Elizabeth M Vaughan http://orcid.org/0000-0001-9565-0134

\section{REFERENCES}

1 Centers for Disease Control and Prevention, US Department of Health and Human Services. National diabetes fact sheet: national estimates and general information on diabetes and prediabetes in the United States. Atlanta: CDC, 2020

2 International Diabetes Federation. International diabetes atlas. 9th edn, 2019. https://www.idf.org/e-library/epidemiology-research/ diabetes-atlas

3 Vega WA, Rodriguez MA, Gruskin E. Health disparities in the Latino population. Epidemiol Rev 2009;31:99-112.

4 American Diabetes Association. Economic costs of diabetes in the U.S. in 2017. Diabetes Care 2018;41:917-28.

5 Rowley WR, Bezold C, Arikan Y, et al. Diabetes 2030: insights from yesterday, today, and future trends. Popul Health Manag 2017;20:6-12.

6 Gandhi M, Raj T, Fernandez R, et al. Mentoring the mentors: implementation and evaluation of four Fogarty-Sponsored mentoring training workshops in Low-and middle-income countries. Am J Trop Med Hyg 2019;100:20-8.

7 Vaughan EM, Hyman DJ, Naik AD, et al. A Telehealth-supported, integrated care with $\mathrm{CHWs}$, and MEdication-access (time) program for diabetes improves HbA1c: a randomized clinical trial. J Gen Intern Med 2021:36:455-63.

8 Edelman D, Gierisch JM, McDuffie JR, et al. Shared medical appointments for patients with diabetes mellitus: a systematic review. J Gen Intern Med 2015;30:99-106.

9 Housden LM, Wong ST. Using group medical visits with those who have diabetes: examining the evidence. Curr Diab Rep 2016;16:134

10 Naik AD, Palmer N, Petersen NJ, et al. Comparative effectiveness of goal setting in diabetes mellitus group clinics: randomized clinical trial. Arch Intern Med 2011:171:453-9.

11 Vaughan EM, Johnston CA, Arlinghaus KR, et al. A narrative review of diabetes group visits in low-income and underserved settings. Curr Diabetes Rev 2019;15:372-81.

12 Mallow JA, Theeke LA, Barnes ER, et al. Examining dose of diabetes group medical visits and characteristics of the uninsured. West $J$ Nurs Res 2015;37:1033-61.

13 Wadsworth KH, Archibald TG, Payne AE, et al. Shared medical appointments and patient-centered experience: a mixed-methods systematic review. BMC Fam Pract 2019;20:97.

14 Jaber R, Braksmajer A, Trilling JS. Group visits: a qualitative review of current research. J Am Board Fam Med 2006;19:276-90.

15 Texas Department of State Health Services. CHW certification requirements, 2019. Available: https://www.dshs.texas.gov/chw/ CertRequire.aspx [Accessed 25 Jan 2021]

16 Scott K, Beckham SW, Gross M, et al. What do we know about community-based health worker programs? A systematic review of existing reviews on community health workers. Hum Resour Health 2018;16:39.

17 World Health Organization. Who guideline on health policy and system support to optimize community health worker programmes. Geneva, CH: World Health Organization, 2018.

18 Vaughan EM, Johnston CA, Cardenas VJ, et al. Integrating CHWs as part of the team leading diabetes group visits: a randomized controlled feasibility study. Diabetes Educ 2017;43:589-99.

19 Wolfe HL, Baughman A, Davoust M, et al. Client satisfaction with community health workers in HIV care teams. $J$ Community Health 2021. doi:10.1007/s10900-021-00978-1. [Epub ahead of print: 26 Mar 2021].

20 Vaughan EM, Naik AD, Lewis CM, et al. Telemedicine training and support for community health workers: improving knowledge of diabetes. Telemed J E Health 2020;26:244-50.

21 Akinla O, Hagan P, Atiomo W. A systematic review of the literature describing the outcomes of near-peer mentoring programs for first year medical students. BMC Med Educ 2018;18:98.
22 Katzmarzyk PT, Martin CK, Newton RL, et al. Weight Loss in Underserved Patients - A Cluster-Randomized Trial. N Engl J Med 2020;383:909-18.

23 OhMD. The modern healthcare communication platform, 2021. Available: https://www.ohmd.com [Accessed 2 Jun 2021].

24 ZOOM. Zoom for healthcare, 2021. Available: https://zoom.us/ healthcare [Accessed 2 Jun 2021].

25 American Diabetes Association. Standards of medical care in diabetes 2021. Diabetes Care 2021;42:S1-193.

26 Garber AJ, Handelsman Y, Grunberger G, et al. Consensus Statement by the American Association of Clinical Endocrinologists and American College of Endocrinology on the Comprehensive Type 2 Diabetes Management Algorithm - 2020 Executive Summary. Endocr Pract 2020;26:107-39.

27 James PA, Oparil S, Carter BL, et al. 2014 evidence-based guideline for the management of high blood pressure in adults: report from the panel members appointed to the eighth joint National Committee (JNC 8). JAMA 2014;311:507-20.

28 Stone NJ, Robinson JG, Lichtenstein AH, et al. 2013 ACC/ AHA guideline on the treatment of blood cholesterol to reduce atherosclerotic cardiovascular risk in adults: a report of the American College of Cardiology/American heart association Task force on practice guidelines. J Am Coll Cardiol 2014;63:2889-934.

29 Zweben A, Fucito LM, O'Malley SS. Effective strategies for maintaining research participation in clinical trials. Drug Inf $J$ 2009;43:459-67.

$30 \mathrm{Li}$ J, Hinami K, Hansen LO, et al. The physician mentored implementation model: a promising quality improvement framework for health care change. Acad Med 2015;90:303-10.

31 Radin MS. Pitfalls in hemoglobin A1c measurement: when results may be misleading. J Gen Intern Med 2014;29:388-94.

32 Efird J. Blocked randomization with randomly selected block sizes. Int J Environ Res Public Health 2011;8:15-20.

33 Lam WY, Fresco P. Medication adherence measures: an overview. Biomed Res Int 2015;2015:1-12.

34 Marcum ZA, Driessen J, Thorpe CT, et al. Effect of multiple pharmacy use on medication adherence and drug-drug interactions in older adults with Medicare Part D. J Am Geriatr Soc 2014;62:244-52.

35 Borneman T, Ferrell B, Puchalski CM. Evaluation of the FICA tool for spiritual assessment. J Pain Symptom Manage 2010;40:163-73.

36 Keegan CN, Johnston CA, Cardenas VJ, et al. Evaluating the impact of telehealth-based, diabetes medication training for community health workers on glycemic control. J Pers Med 2020;10:121-15

37 Garcia AA, Villagomez ET, Brown SA, et al. The Starr County diabetes education study: development of the Spanish-language diabetes knowledge questionnaire. Diabetes Care 2001;24:16-21.

38 Burke RE, O'Grady ET. Group visits hold great potential for improving diabetes care and outcomes, but best practices must be developed. Health Aff 2012:31:103-9.

39 Moore CG, Carter RE, Nietert PJ, et al. Recommendations for planning pilot studies in clinical and translational research. Clin Trans/ Sci 2011;4:332-7.

40 Faul F, Erdfelder E, Lang A-G, et al. G*Power 3: a flexible statistical power analysis program for the social, behavioral, and biomedical sciences. Behav Res Methods 2007;39:175-91.

41 Sambunjak D, Straus SE, Marusic A. A systematic review of qualitative research on the meaning and characteristics of mentoring in academic medicine. J Gen Intern Med 2010;25:72-8.

42 Cené CW, Haymore LB, Ellis D, et al. Implementation of the power to prevent diabetes prevention educational curriculum into rural African American communities: a feasibility study. Diabetes Educ 2013;39:776-85.

43 Palmas W, March D, Darakjy S, et al. Community health worker interventions to improve glycemic control in people with diabetes: a systematic review and meta-analysis. $J$ Gen Intern Med 2015;30:1004-12.

44 Ortega G, Rodriguez JA, Maurer LR, et al. Telemedicine, COVID-19, and disparities: policy implications. Health Policy Technol 2020;9:368-71. 